\title{
Distribution analysis and dose assessment of radon emitted from monazite-containing mattresses in general residential spaces using computational fluid dynamics
}

ChoongWie Lee

Ulsan National Institute of Science and Technology

Hee Reyoung Kim ( $\sim$ kimhr@unist.ac.kr)

Ulsan National Institute of Science and Technology

\section{Research Article}

Keywords: Radon, Computational fluid dynamics, Dose assessment, Mattress

Posted Date: April 26th, 2021

DOl: https://doi.org/10.21203/rs.3.rs-440341/v1

License: (a) (1) This work is licensed under a Creative Commons Attribution 4.0 International License.

Read Full License 
Original article

Distribution analysis and dose assessment of radon emitted from monazite-containing mattresses in general residential spaces using computational fluid dynamics

\author{
ChoongWie Lee ${ }^{\text {a }}$, Hee Reyoung Kim ${ }^{\mathrm{a}}$ \\ ${ }^{a}$ Ulsan National Institute of Science and Technology, Ulsan 44919
}

\begin{abstract}
Radon-releasing mattresses were found to be manufactured using radium or thorium containing monazite, and a survey by the Korean Nuclear Safety and Security Commission found that some of these products exceeded radiation safety standards. Therefore, this study evaluates the radon distribution resulting from the radon released by such mattresses. For this purpose, Ansys Fluent computational fluid dynamics (CFD) codes were used to analyze the radon distribution in a general living space and to assess the radon exposure of residents. Drawings from the Korea Land and Housing Corporation were analyzed to determine the layout and geometry of a general residential space. The CFD simulation results were used to analyze the radon distribution in this space in terms of the ventilation direction and the distance from the source. The dose was evaluated to determine its radiation safety, and it was found to be less than $0.101 \mathrm{mSv} / \mathrm{year}$; this value is below the International Commission on Radiological Protection's recommendation of $10 \mathrm{mSv} / \mathrm{year}$ and the dose limit of $1 \mathrm{mSv} / \mathrm{year}$ for processed products in South Korea. The proposed method could be used to evaluate radon exposure in different environments to improve the safety of residents.
\end{abstract}

Keywords: Radon, Computational fluid dynamics, Dose assessment, Mattress 


\section{Introduction}

Radon has been designated as a carcinogen by the World Health Organization because its inhalation can cause internal radiation exposure in humans and lead to lung cancer ${ }^{1,2}$. Radon is susceptible to diffusion because of its characteristics due to inert gas, and high radon concentrations can have detrimental effect to the human body ${ }^{3-5}$.

The radioisotopes ${ }^{222} \mathrm{Rn}$ and ${ }^{220} \mathrm{Rn}$ occur naturally through the decay of ${ }^{238} \mathrm{U}$ and ${ }^{232} \mathrm{Th}$, respectively. These radioisotopes are present in rocks, and processing such rocks to make objects can expose humans to the radon that is then continuously released from these objects. In 2018 , radon was detected in some mattresses in South Korea ${ }^{6,7}$. A detector was placed near the mattress, the radon concentration was measured, and a scenario was outlined to evaluate the dose. As a result, it was confirmed that the evaluated doses of some mattresses exceeded the public dose limit of $1 \mathrm{mSv}$. Other mattresses manufactured in a similar manner were then investigated. These investigations revealed that the radonreleasing mattress were manufactured using radium or thorium containing Monazite. Further, a survey by the Korean Nuclear Safety and Security Commission (NSSC) found that some of these products exceeded radiation safety standards. Therefore, the NSSC took measures to collect the mattresses that exceeded the safety standards. To avoid these problems and improve safety, the government is considering measures such as requiring the labeling of naturally radioactive products.

Experiments have been conducted in closed spaces in radiation management areas; however, no clear spaces or exposure scenarios have been investigated for indoor residential spaces. Further, it is difficult to assess residents' safety from radon because it is difficult to establish the distribution of radon sources clearly. If the behavior of radon can be modeled using computational fluid dynamics (CFD), it may be possible to simulate doses according to the radon release, ventilation direction, and residents' locations in an indoor environment. Some studies have performed CFD modeling of radon release and accordingly calculated the radon distribution produced by a specific source ${ }^{8-10}$.

In 2018, the NSSC investigated and reported on the radiation safety of radium or thorium containing mattresses twice. First, the NSSC identified the causes of radon release from mattresses and related 
products. Second, mattress suppliers provided two samples that were expected to release radon to the NSSC. These were evaluated using the Durridge RAD7 radon measuring instrument. The ${ }^{222} \mathrm{Rn}$ and ${ }^{220} \mathrm{Rn}$ concentrations at $2 \mathrm{~cm}, 10 \mathrm{~cm}$, and $50 \mathrm{~cm}$ above the mattress surface were measured, and the annual internal exposure dose was calculated as equation 1 and 2.

$$
H=C \times F \times D \times t
$$

where

$H=$ Annual effective dose $(m S v)$

$C=$ Radon concentration $\left(B q / \mathrm{m}^{3}\right)$

$F=$ Equilibrium factor

$D=$ Dose coeffecient $\left(\frac{m S v}{\left(\frac{B q}{m^{3}}\right) \cdot h}\right)$

$t=$ Dwelling time $(h)$.

Radon's own exposure is not large, but major exposures are caused by radioactivity that occurs when polonium, lead, and bismuth which are daughter nuclides of radon are decayed. Because it is difficult to calculate the inhalation dose by directly measuring the amount of daughter nuclides with short halflife, the concentration ratio at equilibrium between the parent nuclide radon and the daughter nuclides can be used. The Equilibrium factor is considered to account for the ratio between radon and radon daughter nuclides at equilibrium. The International Commission on Radiological Protection(ICRP) collected research data on the dose coefficient of ${ }^{222} \mathrm{Rn}$, They recommended that the effective dose per unit exposure at home as $1.2 \times 10^{-5} \mathrm{mSv} /\left(\mathrm{Bq} \cdot \mathrm{h} / \mathrm{m}^{3}\right)$ with an equilibrium factor of 0.4 for ${ }^{222} \mathrm{Rn}{ }^{11}$. Similarly, United Nations Scientific Committee on the Effects of Atomic Radiation (UNSCEAR) recommended that the effective dose per unit exposure at home as $4.0 \times 10^{-5} \mathrm{mSv} /\left(\mathrm{Bq} \cdot \mathrm{h} / \mathrm{m}^{3}\right)$ with an equilibrium factor of 0.03 for ${ }^{220} \mathrm{Rn}{ }^{12}$. In the previous and current studies, the dose of residents was calculated based on these assumptions. 
Table 1 lists the radon concentrations and doses evaluated in this study. Two scenarios were evaluated for dose assessment. In Scenario 1, a person lies on the mattress for only $10 \mathrm{~h}$ a day for sleep, and in Scenario 2, a person stays on the mattress for $24 \mathrm{~h}$ a day. The dose assessment results for Scenario 1 revealed a highest dose of $0.17 \mathrm{mSv} / \mathrm{year}$ at $2 \mathrm{~cm}$ above the mattress, where radon has a long dwelling time. Therefore, the survey results showed that the internal exposure did not exceed the recommended dose limit.

From a height of $2 \mathrm{~cm}$ to $10 \mathrm{~cm}$ above the mattress, ${ }^{222} \mathrm{Rn}$ decreased by $56 \%$. However, from a height of $10 \mathrm{~cm}$ to $50 \mathrm{~cm}$, the change in ${ }^{222} \mathrm{Rn}$ concentration could not be distinguished clearly. It is difficult to derive the correlation between the ${ }^{222} \mathrm{Rn}$ concentration and the distance because the fluctuation of the radon concentration is small compared to the fluctuation of the background in the measured results.

The first survey was conducted for two more weeks, and the doses were assessed by analyzing the radon concentrations at a 2 -cm height for 41 mattress models. As a result, 21 of 41 models were found to release radon in doses exceeding the recommended dose limit. Accordingly, the government implemented administrative measures for radon collection and disposal. Table 2 lists the measurement data of the ${ }^{222} \mathrm{Rn}$ survey for some mattress models.

In light of this assessment, the NSSC established guidelines for evaluating mattresses; however, these methods have limited survey points, making it difficult to determine the radon distribution in daily life. Therefore, mathematical analysis can be used to check the distribution of the radon concentration to cope with complex scenarios.

The present study evaluates the radon distribution resulting from radium or thorium containing mattresses based on previous results of radon release from mattresses ${ }^{13}$. For these evaluations, the Ansys Fluent CFD code was used to analyze the radon distribution in a general living space and to assess residents' radon exposure. 


\section{Materials and methods}

\subsection{Simulation framework}

Radon is generated as it decays in the radium of the material in the mattress, and radon easily escapes and is released to the surroundings due to its inert gas properties. The model assumes that the air flow inside the room is continuous and incompressible ${ }^{14}$. For this simulation, the continuity and momentum conservation respectively given by equations (2) and (3), in which the steady state is assumed, are used to analyze the air flow in the room ${ }^{15}$.

$$
\begin{gathered}
\nabla \cdot \rho u_{i}=0 \\
\rho\left(u_{j} \cdot \nabla\right) u_{i}=-\nabla \mathrm{P}+\nabla \cdot\left(\mu_{e} \nabla \mathrm{u}_{\mathrm{i}}\right)+\mathrm{F}_{\mathrm{i}}
\end{gathered}
$$

$$
\begin{aligned}
& \text { where } \\
& \begin{array}{l}
u=\text { velocity }(\mathrm{m} / \mathrm{s}) \\
P=\operatorname{pressure}\left(\mathrm{N} / \mathrm{m}^{2}\right)
\end{array} \\
& \mu_{e}=\text { effective viscosity }\left(\mathrm{N} \cdot \mathrm{s} / \mathrm{m}^{2}\right) \\
& \mathrm{F}_{\mathrm{i}}=\text { body force vector }\left(F_{x}=F_{x}=0, F_{z}=\rho g\right) \\
& \rho=\text { density of air }\left(\mathrm{kg} / \mathrm{m}^{3}\right) \\
& g=\text { acceleration due to gravity }\left(\mathrm{m} / \mathrm{s}^{2}\right)
\end{aligned}
$$

In Eq. (3), no body force acts in the $\mathrm{x}$ and $\mathrm{y}$ directions, whereas a body force acts in the $\mathrm{z}$ direction. The standard $\mathrm{k}-\varepsilon$ model was used to consider a turbulent airflow. Inside the model, the standard $\mathrm{k}-\varepsilon$ model is considered as in equations 4 and $5^{16}$.

$$
\begin{gathered}
\frac{\partial}{\partial t}(\rho \mathrm{k})+\frac{\partial}{\partial x_{i}}\left(\rho \mathrm{ku}_{\mathrm{i}}\right)=\frac{\partial}{\partial x_{j}}\left[\left(\mu+\frac{\mu_{\mathrm{t}}}{\sigma_{k}}\right) \frac{\partial k}{\partial x_{j}}\right]+G_{k}+G_{b}-\rho \epsilon-Y_{M} \\
\frac{\partial}{\partial t}(\rho \epsilon)+\frac{\partial}{\partial x_{i}}\left(\rho \epsilon \mathrm{u}_{\mathrm{i}}\right)=\frac{\partial}{\partial x_{j}}\left[\left(\mu+\frac{\mu_{\mathrm{t}}}{\sigma_{\epsilon}}\right) \frac{\partial \epsilon}{\partial x_{j}}\right]+C_{1 \epsilon} \frac{\epsilon}{k}\left(G_{k}+G_{k}+C_{3 \epsilon}+G_{b}\right)-C_{2 \epsilon} \rho \frac{\epsilon^{2}}{k}
\end{gathered}
$$


Where

$k=$ turbulence kinetic energy $\left(\mathrm{m}^{2} / \mathrm{s}^{2}\right)$

$\epsilon=$ dissipation rate

$G_{k}=$ The generation of $k$ due to the mean velocity gradients

$G_{k}=$ The generation of $k$ due to buoyancy

$Y_{M}=$ contribution of the fluctuating dilatation

$C_{1 \epsilon}, C_{2 \epsilon}, C_{3 \epsilon}=$ Model constants, $\left(C_{1 \epsilon}=1.44, C_{2 \epsilon}=1.92, C_{3 \epsilon}=0.09\right)$

$\sigma_{k}, \sigma_{\epsilon}=$ the turbulent Prandtl numbers for $k$ and $\epsilon, 1.0,1.3$

In addition, the convection-diffusion equation was used to simulate the radon dispersion, and it should consider the reduction in radon due to its decay. Accordingly, the movement of radon is given by equation $6 .^{17}$

$$
\frac{\partial \mathrm{C}}{\partial t}=\nabla \cdot(D \nabla C)-\nabla \cdot(u C)-\lambda C+S
$$

where

$C=$ Average radon concentration in indoor $\operatorname{air}\left(\mathrm{Bq} / \mathrm{m}^{3}\right)$

$D=$ Diffusion coefficient of radon $\left(\mathrm{m}^{2} / \mathrm{s}\right)=1.2 \times 10^{-5} \mathrm{~m}^{2} / \mathrm{s}$

$\lambda=$ Decay constant $\left(\mathrm{s}^{-1}\right)=2.1 \times 10^{-6} / \mathrm{s}$

$S=$ Radon emission rate $\left(B q / \mathrm{m}^{3} \cdot s\right)$.

For a steady-state simulation, $\frac{\partial \mathrm{C}}{\partial t}=0$. The mass fraction of radon was predicted by solving all relevant equations and then converted to the activity concentration $\left(\mathrm{Bq} / \mathrm{m}^{3}\right)$. Ansys Fluent code was used for the CFD mathematical analysis to simulate the general room structure and evaluate the radon 
distribution. The radionuclide ratio at the source and the release rate inside the mattress were calculated by converting the results of the NSSC's research ${ }^{13}$. The radon activity concentration of $58.5 \mathrm{~Bq} / \mathrm{m}^{3}$ measured at the target's surface was used as the ratio of internal nuclides, and the radon concentration measured at 2-cm height divided by $4 \pi \mathrm{r}$ was used as the radon emission rate.

\subsection{Mathematical modelling}

For modeling a general residential space, the geometric structure of a room obtained from the drawings of the Korea Land and Housing Corporation was analyzed. The room had dimensions of 3.85 $\mathrm{m} \times 2.9 \mathrm{~m}$ and a height of $2.8 \mathrm{~m}$. The mattress had dimensions of $2.07 \mathrm{~m} \times 1.7 \mathrm{~m}$ and a height of 0.3 m, as shown in Figure 1. Figures 2 and 3 show the corresponding structure simulated in Ansys Fluent. The complete volume was meshed in Ansys Fluent using 135,459 structured tetrahedron cells with a minimum volume of $4 \times 10^{-3} \mathrm{~m}^{3}$.

In the simulations, the effects of ventilation must be considered. For this purpose, the inlet velocity is calculated as 15

$$
u_{\text {inlet }}=\frac{\lambda_{\mathrm{v}} V_{\text {Room }}}{A_{\text {Vent }}}
$$

where

$$
\begin{aligned}
& u_{\text {inlet }}=\text { Inlet velocity }(\mathrm{m} / \mathrm{s}) \\
& \lambda_{v}=\text { Air ventilation rate }(/ \mathrm{h}) \\
& A_{\text {Vent }}=\text { Ventilation area }\left(\mathrm{m}^{2}\right) \\
& V_{\text {Room }}=\text { Volume of room }\left(\mathrm{m}^{3}\right)
\end{aligned}
$$

The ventilation rate specified in KSF 2921 (Ventilation Performance Test Method for Natural Ventilation Facilities in Korea) was $0.5 \mathrm{~h}^{-1}$; this value was used in the present study. The inlet velocity due to natural ventilation at the door was calculated to be $0.0027 \mathrm{~m} / \mathrm{s}$. The Reynolds number was calculated as 315; therefore, the fluid in this space has laminar flow. 


\section{Results and discussions}

Figure 4 shows the velocity distribution in the room, and Figure 5 shows the distribution of radon concentrations at 2-, 10-, and 50-cm heights above the mattress analyzed based on the results of the Ansys Fluent simulation.

In Figure 5, the (a) layout and (b), (c), (d) positions are shown to be the same. At 2-cm height, the radon distribution is apparent because it is close to the source. However, as the height increases, the radon concentration decreases, and the distribution is affected by the ventilation.

For detailed distribution analysis, the distributions of the radon concentration in the middle of the mattress $(y=1.4 \mathrm{~m})$ and outside the mattress $(\mathrm{y}=0.2 \mathrm{~m})$ were analyzed, as shown in Figures 6 and 7 , respectively.

In Figure 6, the edge of the mattress can be seen through a large change in radon concentration at both ends of the mattress. In addition, the radon is concentrated depending on the ventilation direction, and this tendency increases as the height increases. At $\mathrm{x}=1.75 \mathrm{~m}$ and $\mathrm{x}=3.25 \mathrm{~m}$, the radon concentration fluctuation varies from 2.00 to $2.38 \mathrm{~Bq} / \mathrm{m}^{3}$ at $2-\mathrm{cm}$ height and from 0.29 to $1.25 \mathrm{~Bq} / \mathrm{m}^{3}$ at $50-\mathrm{cm}$ height. The radon concentration increases from the starting point of the mattress, as shown in Figure 7. Unlike in Figure 6, the radon concentration does not show a large change with height, and the change tends to increase along the flow from the inlet to the outlet. These differences indicate that the ventilation direction and location need to be considered when measuring the radon release rate from the mattress. At 50-cm height, the concentration tends to increase again at $\mathrm{x} \sim 3.75 \mathrm{~m}$ after passing the mattress, which seems to be close to the source-outlet flow of radon in a room with high radon flux.

Therefore, for dose assessment, the concentrations at 2- and 50-cm height were identified at six locations where the human head is expected to lie, as shown in Figure 8. The internal dose was calculated using Eq. (1) for Scenario 2 considering 24-h stay for a conservative assessment. Tables 3 
and 4 respectively show the dose assessments at six points at 2 - and 50 -cm heights. As a result, the concentration of radon was found to vary from 0.453 to $2.35 \mathrm{~Bq} / \mathrm{m}^{3}$. At 2-cm height, the radioactivity at each location was not significantly different because the effect of the source was greater than that of the ventilation. Thus, assuming a long distance from the mattress, it may be reasonable to assess residents' dose using this CFD code. The maximum dose was evaluated to be $0.101 \mathrm{mSv}$, and the International Commission on Radiological Protection's recommended dose limit was $10 \mathrm{mSv}$; therefore, the evaluation result was lower than the recommended dose ${ }^{18}$. In South Korea, the public's radiation exposure via processed products is limited to $1 \mathrm{mSv} / \mathrm{year}$. The evaluation results indicate that the internal dose will be lower than this standard if the level of natural ventilation is maintained.

\section{Conclusions}

This study confirmed the NSSC's radon analysis results of 2018 for radon-releasing mattresses and analyzed the radon concentration in indoor environments using Ansys Fluent for a general residential space. Radon concentrations were assessed according to the head position on the mattress, and the dose was evaluated based on these results. In actual living conditions, the ventilation pattern in the sleeping environment may differ from the average one, and other mattresses reported to release radon as well as the interim NSSC announcement may have different results.

These methods can be used to confirm the distribution of radon released from mattresses and be applied to other radon-releasing materials, including mattresses, to analyze the corresponding radon distribution and to assess residents' dose. This analytical method can be used to determine the radon distribution in a complex space containing multiple radon emitters and to accordingly study and regulate indoor radon distributions.

\section{Acknowledgments}


This work was supported by the National Research Foundation of Korea (NRF) grant funded by the Korean government (Ministry of Science, ICT and Future Planning (MSIP), grant nos. NRF2016M2B2B1945082 and NRF-22A20153413555). 



\section{Reference}

1 EPA. Agency. EPA assessment of risks from radon in homes. EPA 402-R-03-003. Washington. (2003).

2 WHO. WHO handbook on indoor radon: a public health perspective. (World Health Organization, 2009).

3 Ye, W. et al. Mortality and cancer incidence in Misasa, Japan, a spa area with elevated radon levels. Cancer Science 89, 789-796 (1998).

4 Kreuzer, M., Walsh, L., Schnelzer, M., Tschense, A. \& Grosche, B. Radon and risk of extrapulmonary cancers: results of the German uranium miners' cohort study, 1960-2003. British journal of cancer 99, 1946-1953 (2008).

5 Auvinen, A. et al. Radon and other natural radionuclides in drinking water and risk of stomach cancer: A case-cohort study in Finland. international Journal of Cancer 114, 109-113 (2005).

6 Seo, S. et al. Health effects of exposure to radon: implications of the radon bed mattress incident in Korea. Epidemiology and health 41 (2019).

7 Seo, S., Kang, J.-K., Lee, D. \& Jin, Y. W. Health effects and consultations about radon exposure. Journal of the Korean Medical Association 62, 376-382 (2019).

8 Hoang, S. M. T., Sun, G. M., Kim, J., Lee, H. R. \& Baek, H. 3d radon distribution modelling in the typical korean house based on CFD code.

9 Akbari, K., Mahmoudi, J. \& Ghanbari, M. Influence of indoor air conditions on radon concentration in a detached house. Journal of environmental radioactivity 116, 166-173 (2013).

10 Akbari, K. Simulation of Indoor Radon and Energy Recovery Ventilation Systems in Residential Buildings, Mälardalen University, (2015).

11 Tirmarche, M. et al. ICRP Publication 115. Lung cancer risk from radon and progeny and statement on radon. Annals of the ICRP 40, 1-64 (2010).

12 Harrison, J. \& Marsh, J. Effective dose from inhaled radon and its progeny. Annals of the ICRP 41, 378-388 (2012).

13 NSSC.

14 Boussinesq, J. Théorie des ondes et des remous qui se propagent le long d'un canal rectangulaire horizontal, en communiquant au liquide contenu dans ce canal des vitesses sensiblement pareilles de la surface au fond. Journal de mathématiques pures et appliquées, 55-108 (1872).

15 Zhou, W., Iida, T., Moriizumi, J., Aoyagi, T. \& Takahashi, I. Simulation of the concentrations and distributions of indoor radon and thoron. Radiation protection dosimetry 93, 357-367 (2001).

16 Launder, B. \& Spalding, D. Lectures in Mathematical Models of Turbulence, Academic Press, London, 1972. Collebrook CFD.

17 Visnuprasad, A., Roy, K. R., Jojo, P. \& Sahoo, B. Comparison of results from indoor radon measurements using active and passive methods with those from mathematical modeling. Radiation and environmental biophysics 58, 345-352 (2019).

18 Clement, C. H. et al. Lung cancer risk from radon and progeny and statement on radon. Annals of the ICRP 40, 1-64 (2010). 


\section{Figure captions}

Figure 1 Actual figure of the mattress decided for simulation

Figure 2 Geometry of general residential space

Figure 3 Layout and coordinates of general residential space

Figure 4 3D distribution of velocity

Figure 5 3D distribution result of Radon concentration. (a) layout and ${ }^{222} \mathrm{Rn}$ concentration at (b) $2 \mathrm{~cm}$ height, (c) $10 \mathrm{~cm}$ height, (d) $50 \mathrm{~cm}$ height

Figure 6 Radon concentration at $2 \mathrm{~cm}, 10 \mathrm{~cm}$ and $50 \mathrm{~cm}$ height from mattress at the center of bed (y $=1.4 \mathrm{~m})$

Figure 7 Radon concentration at $2 \mathrm{~cm}, 10 \mathrm{~cm}$ and $50 \mathrm{~cm}$ height from mattress at the outside of bed (y $=0.2 \mathrm{~m})$

Figure 8 Selection of 6 points for dose assessment

\section{Table captions}

Table 1 Radon concentration measurement result of intermediate survey from NSSC

Table 2 Measurement data of ${ }^{222} \mathrm{Rn}$ survey for a some of the model

Table $3{ }^{222} \mathrm{Rn}$ concentration and dose evaluation result at 6 points at $2 \mathrm{~cm}$ height

Table $4{ }^{222} \mathrm{Rn}$ concentration and dose evaluation result at 6 points at $50 \mathrm{~cm}$ height 


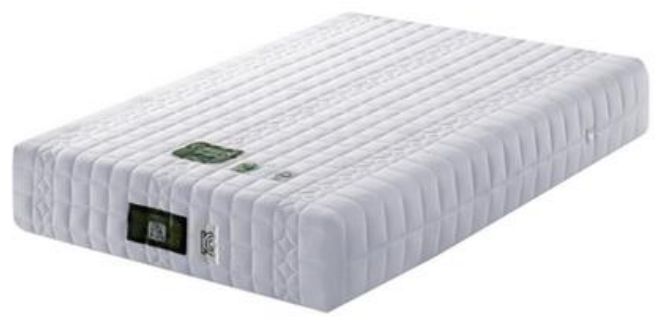

Fig 1.

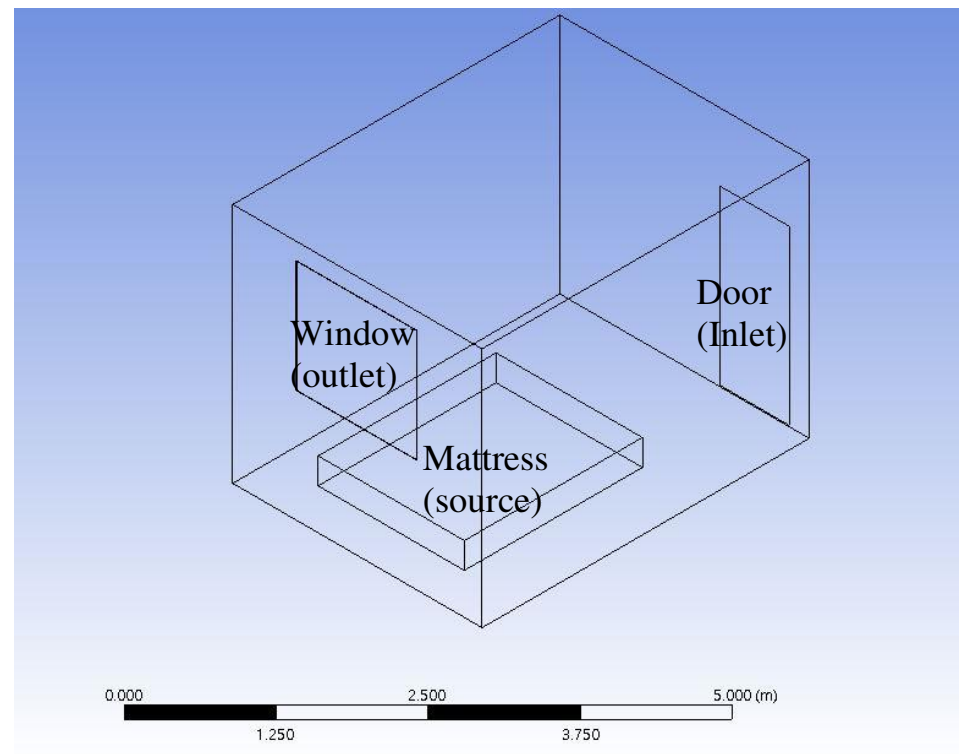

Fig 2.

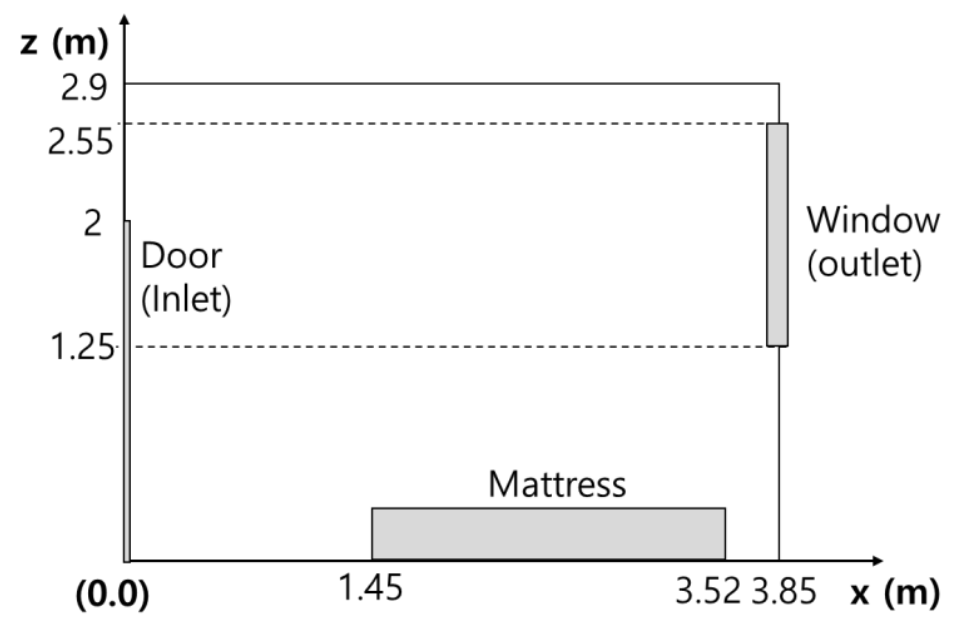

Fig 3. 


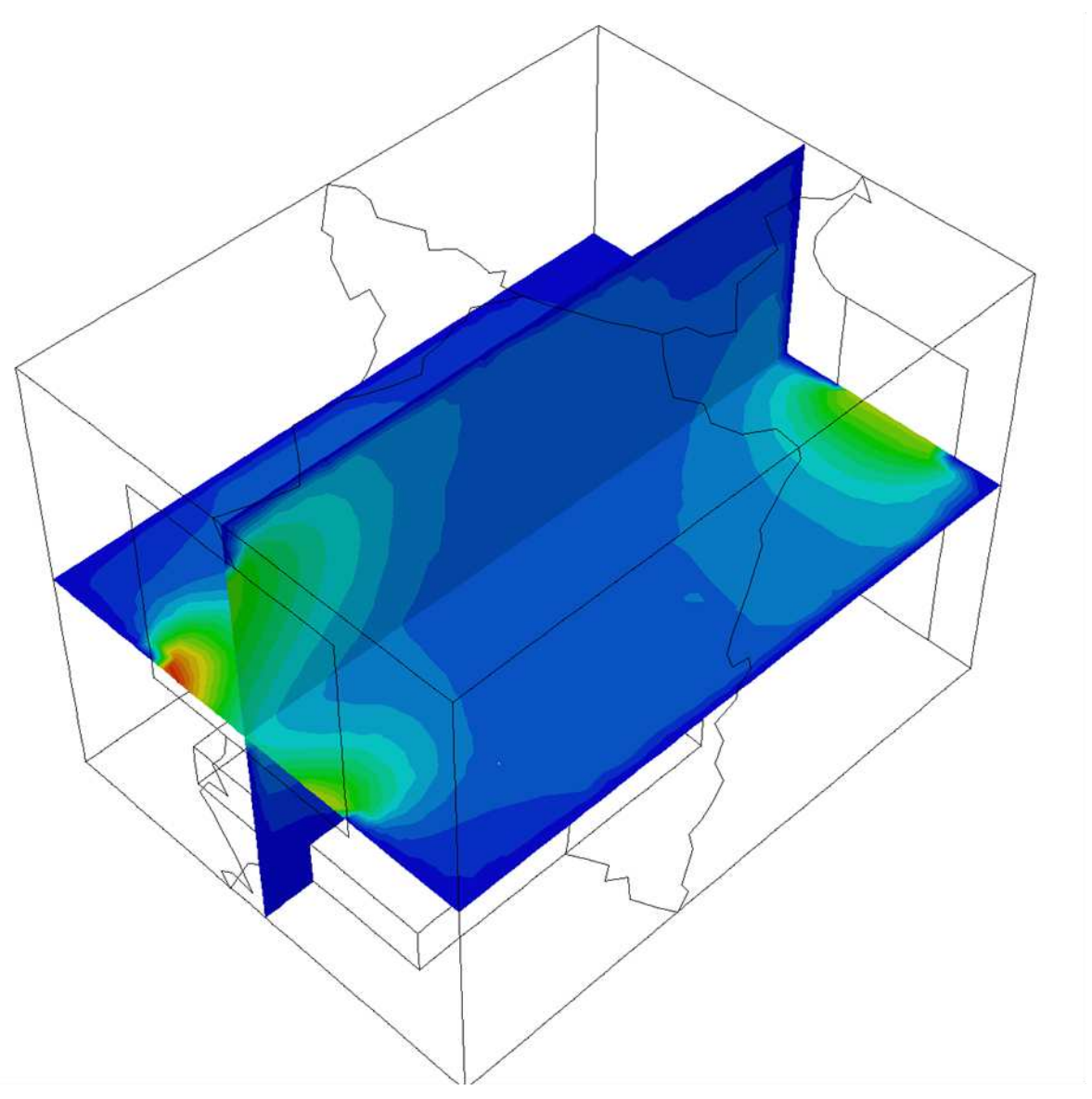

Velocity $(\mathrm{m} / \mathrm{s})$

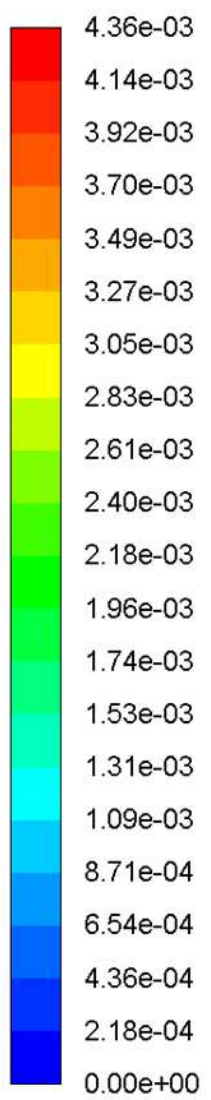

Fig 4.

(a)

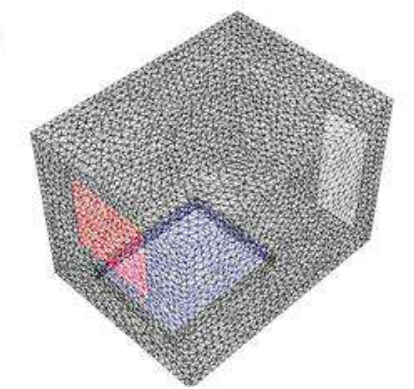

(c)

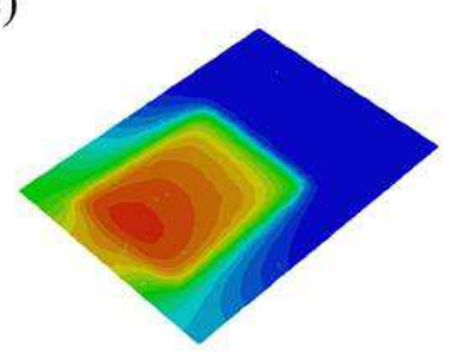

(b)

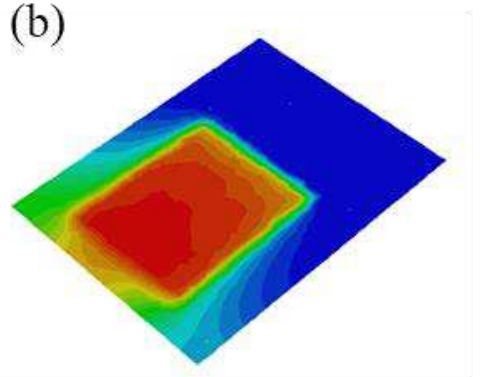

(d)

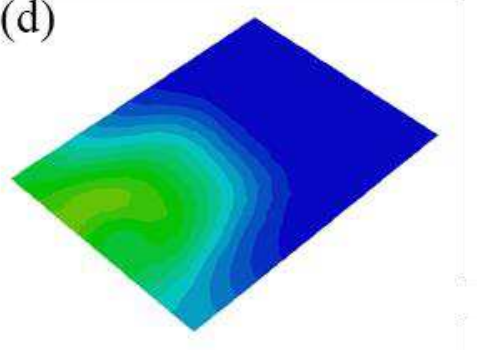

$2.44 \mathrm{e}+00 \quad{ }^{222} \mathrm{Rn}$

$2.19 \mathrm{e}+00$ concentration

$2.07 \mathrm{e}+00\left(\mathrm{~Bq} / \mathrm{m}^{3}\right)$

$1.95 \mathrm{e}+00$

$1.70 e+00$

$1.58 \mathrm{e}+00$

$1.46 \mathrm{e}+00$

$1.34 \mathrm{e}+00$

$1.22 \mathrm{e}+00$

$1.10 e+00$

$9.74 \mathrm{e}-01$

8.52e-01

7.31e-01

$6.09 \mathrm{e}-01$

4.87e-01

3.65e-01

2. $44 \mathrm{e}-01$

$1.22 \mathrm{e}-01$

$0.00 e+00$

Fig 5. 


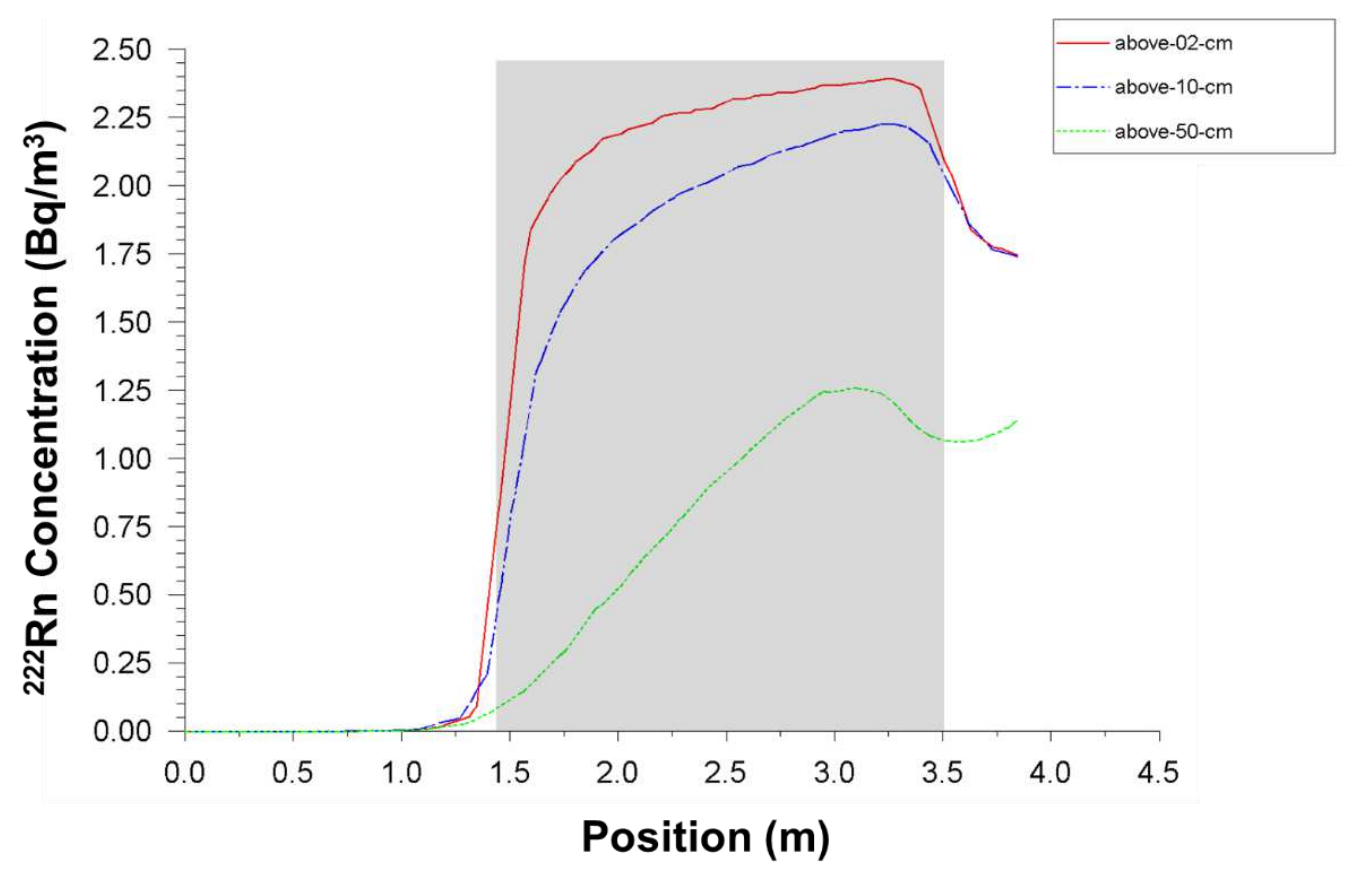

Fig 6.

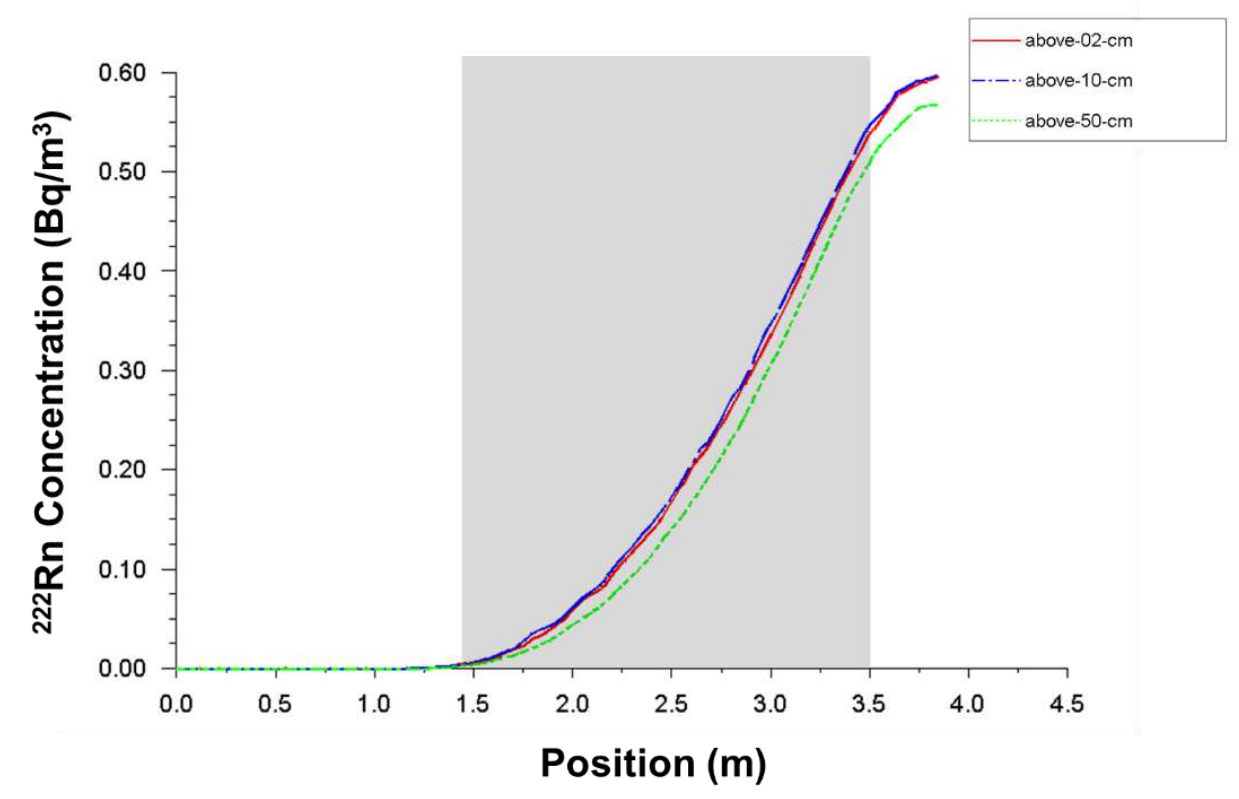

Fig 7. 


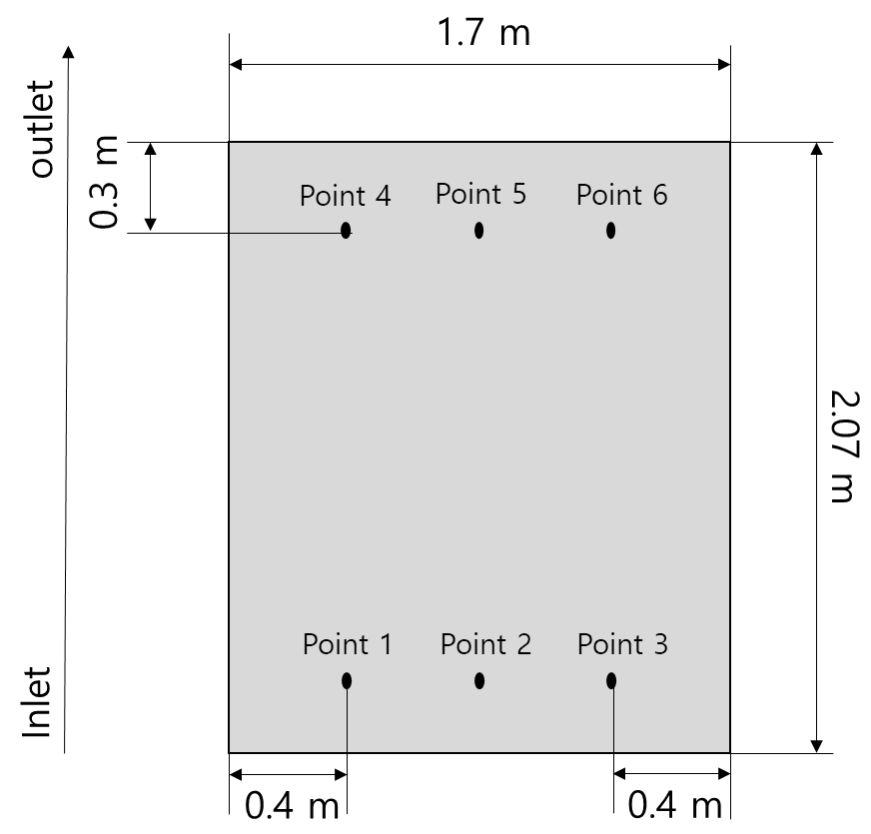

Fig 8. 
Table 1.

\begin{tabular}{|c|c|c|c|c|c|c|}
\hline $\begin{array}{c}\text { Measurement } \\
\text { Location }\end{array}$ & $\begin{array}{c}\text { Distance } \\
(\mathrm{cm})\end{array}$ & $\begin{array}{c}{ }^{222} \mathrm{Rn} \\
\text { concentration } \\
\left(\mathrm{Bq} / \mathrm{m}^{3}\right)\end{array}$ & $\begin{array}{c}{ }^{222} \mathrm{Rn} \\
\text { Background } \\
\left(\mathrm{Bq} / \mathrm{m}^{3}\right)\end{array}$ & $\begin{array}{c}{ }^{222} \mathrm{Rn} \text { emission } \\
\left(\mathrm{Bq} / \mathrm{m}^{3}\right)\end{array}$ & $\begin{array}{c}\text { Annual dose at } \\
\text { Scenario 1 } \\
(\mathrm{mSv} / \mathrm{y})\end{array}$ & $\begin{array}{c}\text { Annual dose at } \\
\text { Scenario 2 } \\
(\mathrm{mSv} / \mathrm{y})\end{array}$ \\
\hline \multirow{2}{*}{$\begin{array}{c}\text { height from } \\
\text { mattress }\end{array}$} & 2 & 24.2 & 15.0 & 9.20 & 0.16 & 0.39 \\
\cline { 2 - 7 } & 10 & 14.0 & 8.83 & 5.17 & 0.09 & -22 \\
\hline
\end{tabular}

Scenario 1: Assume 10 hours a day residence at the distance

Scenario 2: Assume 24 hours a day residence at the location

Table 2 .

\begin{tabular}{|c|c|c|}
\hline Model & ${ }^{222} \mathrm{Rn}$ concentration $\left(\mathrm{Bq} / \mathrm{m}^{3}\right)$ & $\begin{array}{c}\text { Annual dose by }{ }^{222} \mathrm{Rn} \\
(\mathrm{mSv} / \mathrm{year})\end{array}$ \\
\hline Mattress A & 35.13 & 0.39 \\
\hline Mattress B & 61.54 & 0.69 \\
\hline Mattress C & 68.08 & 0.76 \\
\hline Mattress D & 12.18 & 0.14 \\
\hline Mattress E & 1.08 & 0.01 \\
\hline Mattress F & 14.18 & 0.16 \\
\hline
\end{tabular}

Table 3.

\begin{tabular}{|c|c|c|}
\hline Position (m) & $\begin{array}{c}\text { Annual dose by }{ }^{222} \mathrm{Rn} \\
\left(\mathrm{Rn} \text { concentration }\left(\mathrm{Bq} / \mathrm{m}^{3}\right)\right.\end{array}$ \\
\hline Point 1 & $2.13 \mathrm{E}+00$ & $9.01 \mathrm{E}-02$ \\
\hline Point 2 & $2.10 \mathrm{E}+00$ & $8.90 \mathrm{E}-02$ \\
\hline Point 3 & $2.05 \mathrm{E}+00$ & $8.69 \mathrm{E}-02$ \\
\hline Point 4 & $2.38 \mathrm{E}+00$ & $1.01 \mathrm{E}-01$ \\
\hline Point 5 & $2.38 \mathrm{E}+00$ & $1.01 \mathrm{E}-01$ \\
\hline Point 6 & $2.35 \mathrm{E}+00$ & $9.96 \mathrm{E}-02$ \\
\hline
\end{tabular}


Table 4.

\begin{tabular}{|c|c|c|}
\hline Position $(\mathrm{m})$ & $\begin{array}{c}{ }^{222} \mathrm{Rn} \text { concentration }\left(\mathrm{Bq} / \mathrm{m}^{3}\right) \\
\text { Annual dose by }{ }^{222} \mathrm{Rn} \\
(\mathrm{mSv} / \mathrm{year})\end{array}$ \\
\hline Point 1 & $4.53 \mathrm{E}-01$ & $1.92 \mathrm{E}-02$ \\
\hline Point 2 & $3.91 \mathrm{E}-01$ & $1.66 \mathrm{E}-02$ \\
\hline Point 3 & $3.00 \mathrm{E}-01$ & $1.27 \mathrm{E}-02$ \\
\hline Point 4 & $1.44 \mathrm{E}+00$ & $6.08 \mathrm{E}-02$ \\
\hline Point 5 & $1.47 \mathrm{E}+00$ & $6.21 \mathrm{E}-02$ \\
\hline Point 6 & $1.23 \mathrm{E}+00$ & $5.19 \mathrm{E}-02$ \\
\hline
\end{tabular}


Figures

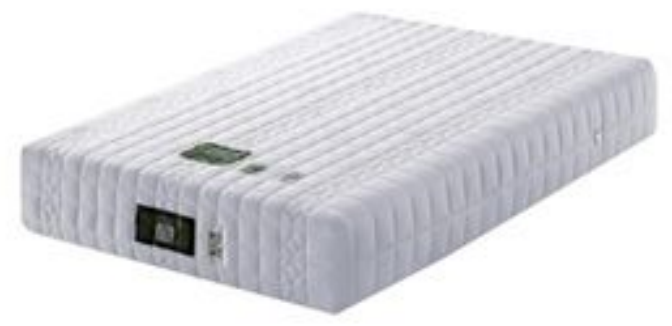

Figure 1

Actual figure of the mattress decided for simulation

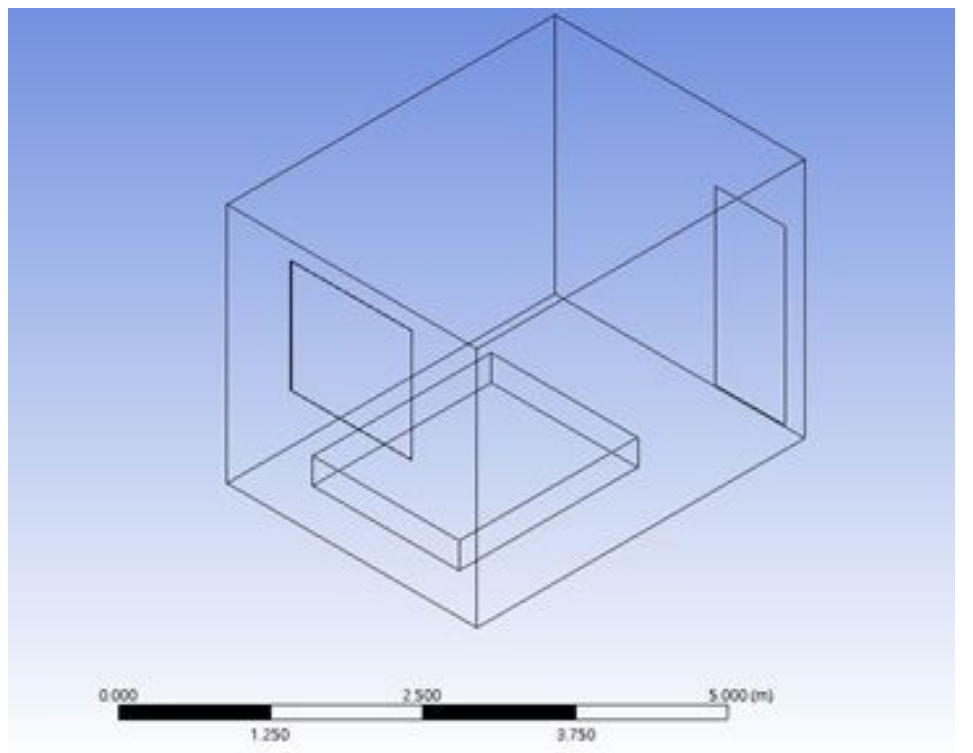

Figure 2

Geometry of general residential space

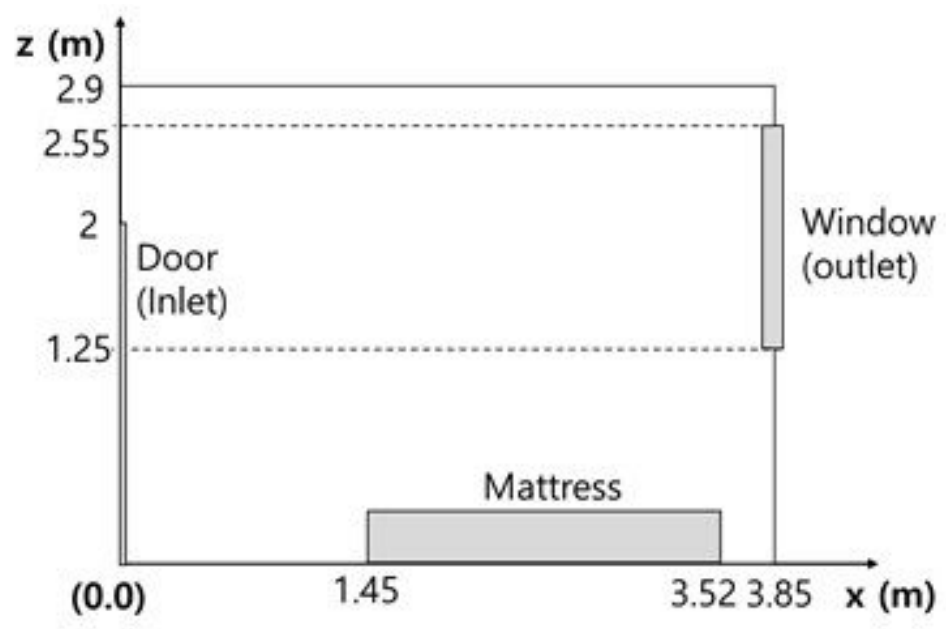

Figure 3 


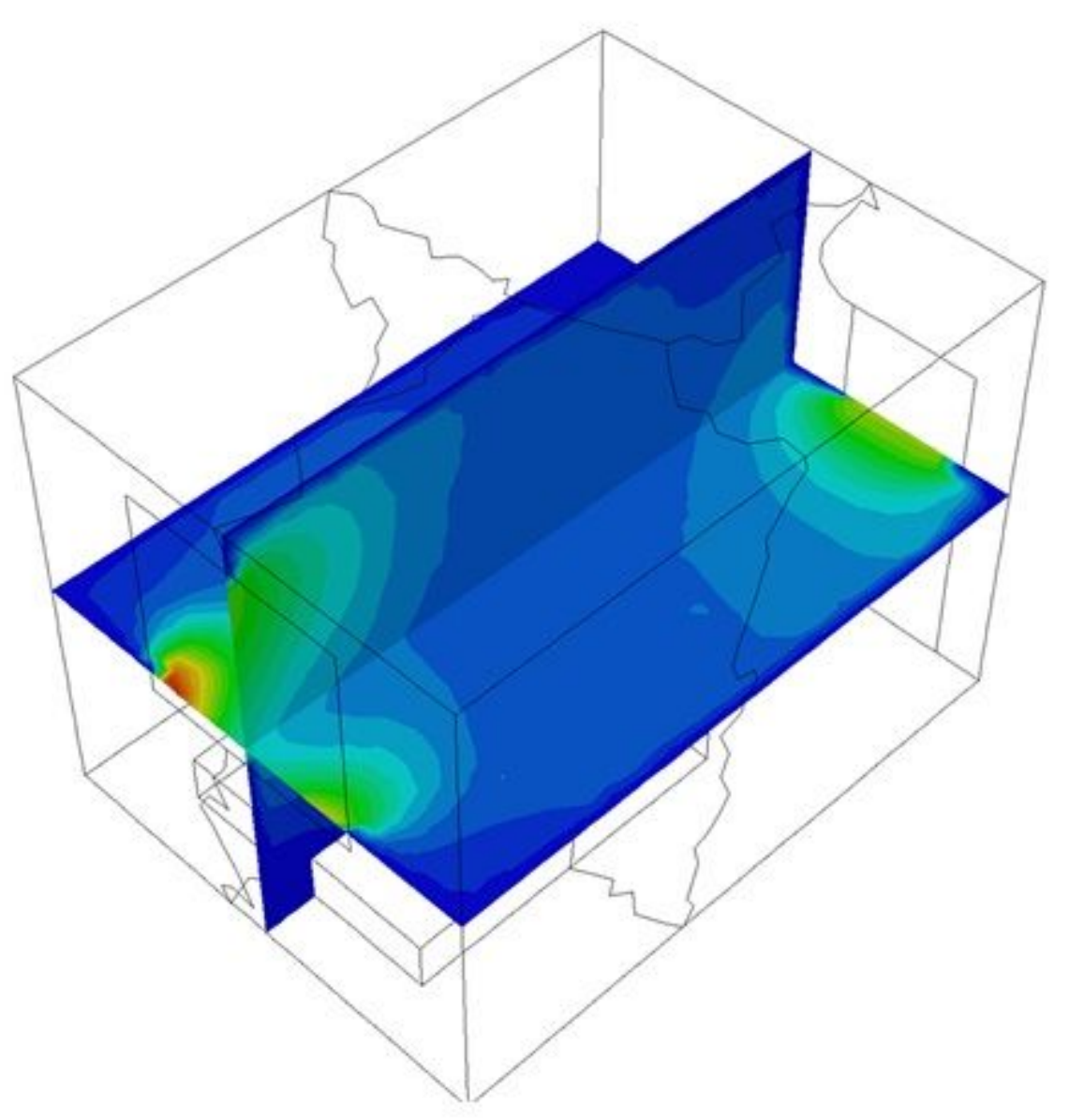

Velocity $(\mathrm{m} / \mathrm{s})$

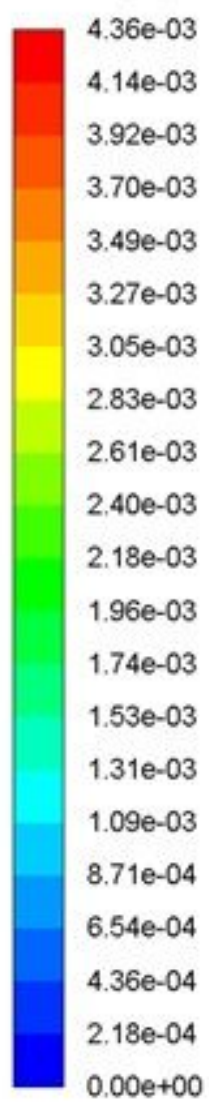

\section{Figure 4}

3D distribution of velocity

(a)

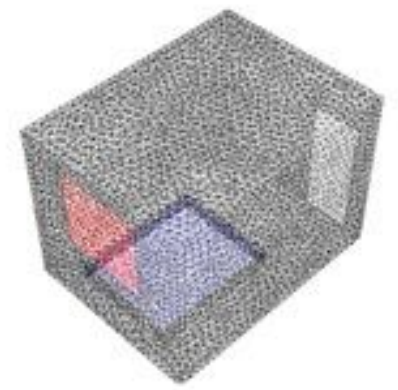

(c)

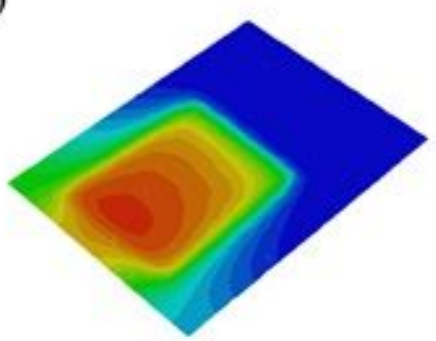

(b)

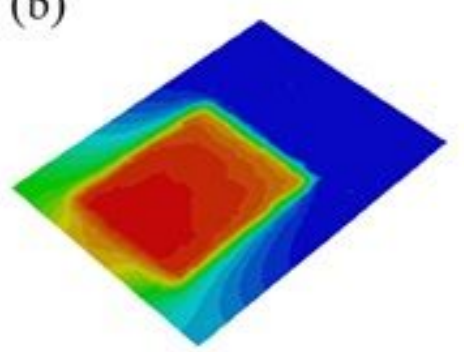

(d)

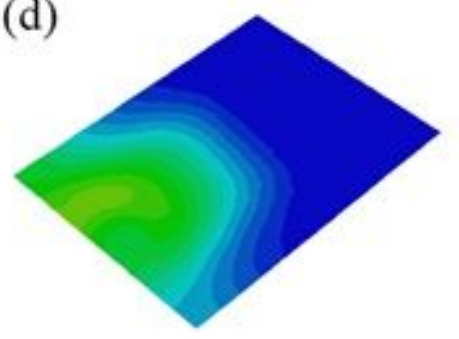

$2.44 \mathrm{e}+00$ $2.31 \mathrm{e}+00$ $2.19 e+00$ concentration

$2.07 \mathrm{e}+00$

$1.95 \mathrm{e}+00\left(\mathrm{~Bq} / \mathrm{m}^{3}\right)$

$1.83 e * 00$

$1.70 \mathrm{e}+00$

$1.58 \mathrm{e}+00$

$1.46 \mathrm{e}+00$

$1.34 \mathrm{e} * 00$

$1.22 \mathrm{e} * 00$

$1.10 \mathrm{e}+00$

$9.74 \mathrm{e}-01$

$8.52 \mathrm{e}-01$

7.31e-01

6.09e-01

$4.87 \mathrm{e}-01$

3.65e-01

2. $44 \mathrm{e}-01$

1.22e-01

$0.00 \mathrm{e}+00$

Figure 5 
3D distribution result of Radon concentration. (a) layout and 222Rn concentration at (b) $2 \mathrm{~cm}$ height, (c) $10 \mathrm{~cm}$ height, (d) $50 \mathrm{~cm}$ height

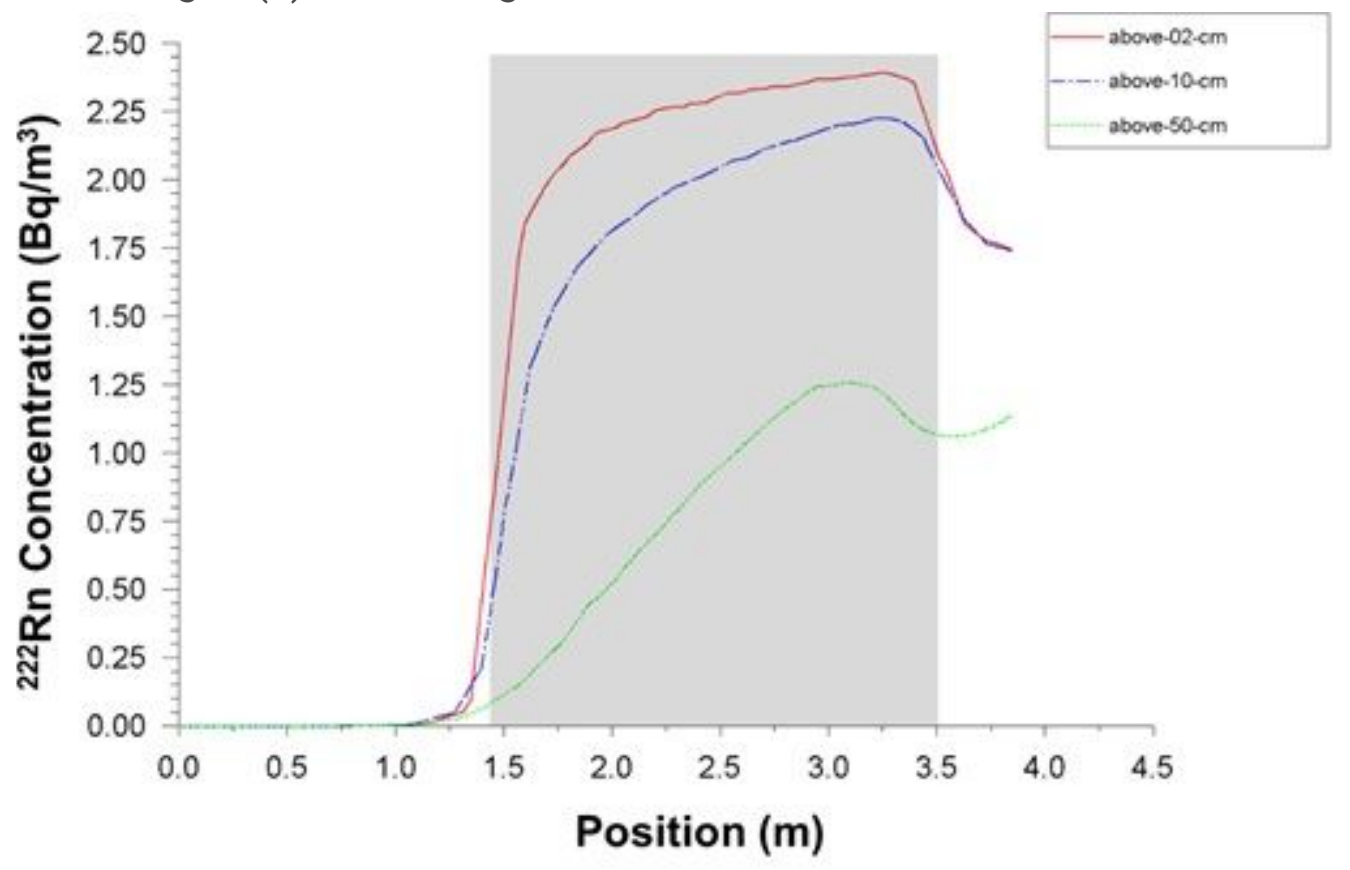

Figure 6

Radon concentration at $2 \mathrm{~cm}, 10 \mathrm{~cm}$ and $50 \mathrm{~cm}$ height from mattress at the center of bed $(y=1.4 \mathrm{~m})$

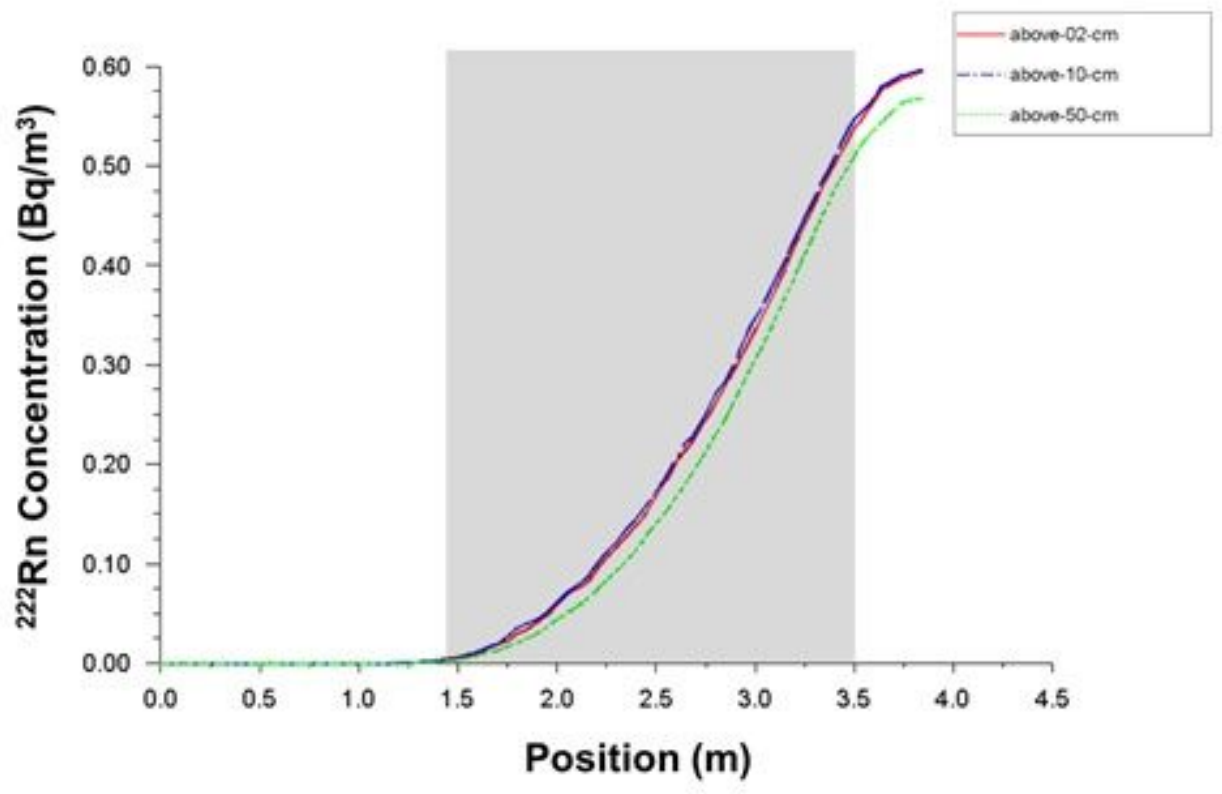

Figure 7

Radon concentration at $2 \mathrm{~cm}, 10 \mathrm{~cm}$ and $50 \mathrm{~cm}$ height from mattress at the outside of bed $(y=0.2 \mathrm{~m})$ 


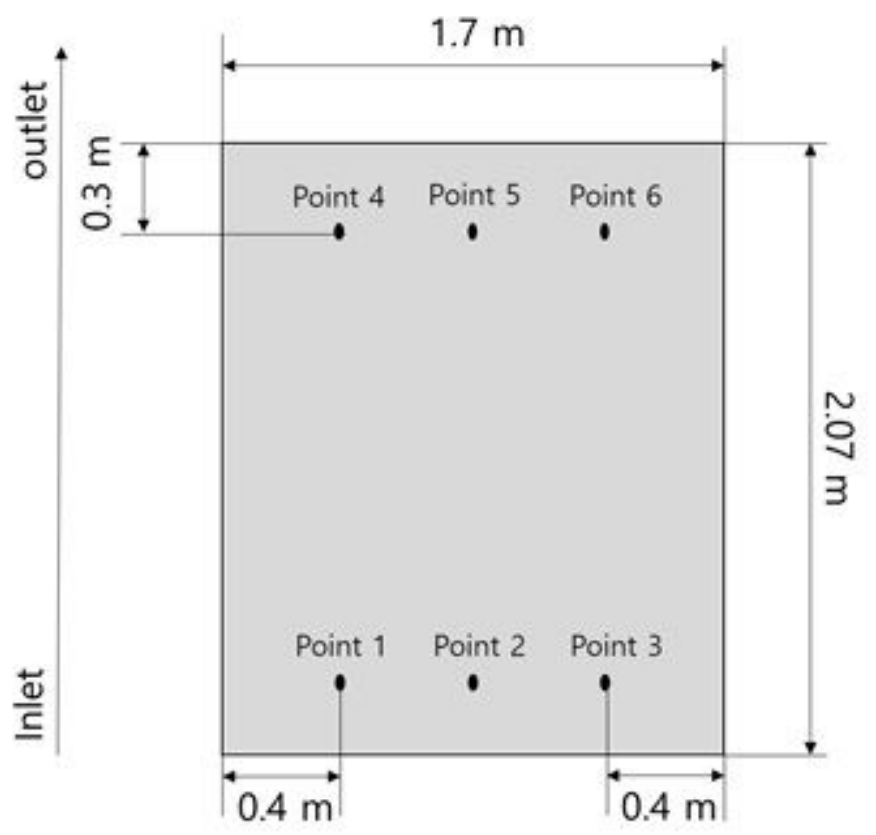

Figure 8

Selection of 6 points for dose assessment 